Local Anaesthetics Containing Vasoconstrictors

SIR,-Your editorial "Local Anaesthetics Containing Vasoconstrictors" (12 December, p. 633) quite rightly stresses the dangers of using vasoconstrictors in combination with local analgesic solutions when operating on the extremities. However, the use of these catecholamines on patients taking tricyclic antidepressant drugs was not sufficiently stressed. It must be remembered that the injection of any local analgesic solution could inadvertently be intravascular, particularly in dental procedures. This might precipitate a hypertensive episode of a dangerous nature, for recent investigations have shown that noradrenaline and, to a lesser degree, adrenaline may produce a significant rise in blood pressure if given intravenously to volunteers who were at the same time receiving an antidepressant agent of the tricyclic type.

Still more recently, this effect has been studied in $\operatorname{dogs}^{2}$ and the results have been confirmed using small intravenous doses of readily available analgesic solutions employed in dental surgery. It has also been shown that felypressin (Octopressin) is not potentiated by the tricyclic antidepressants. ${ }^{3}$ When employed in combination with local analgesic solutions intravenous injections did not produce significant changes even in twice the dosage used of solutions containing catecholamines. $^{2}$ A solution containing prilocaine $3 \%$ and felypressin 0.03 i.u. $/ \mathrm{ml}$ is now available and has been found to be readily acceptable in dental practice. ${ }^{4}$ It would seem reasonable for this solution to be employed whenever there is a possibility of a patient being under treatr.ent with a tricyclic antidepressant ${ }^{5}-\mathrm{I}$ am, etc.,

\section{VICTOR GOLDMAN}

London W.1

1 Svedmyr, N., Life Sciences, 1968, 7, No. 1 2 Goldman, v., Åstrom, A., and Evers, H., Proceedings of the Third Asian and Australasia A.ongress of Anaesthesiology, London, 1970. of Anaesthesiology. London, 1968 . of Anaesthesiology. London, 1968.
Goldman, V. and Evers, H. Dental Practitioner
and Dental Record, 1969, 19, 225. Garland, W. H.. British Dental fournal, 1970.
129, 265.

\section{Benign Prostatic Enlargement}

SIR,-Professor J. P. Blandy gives us a clear summary of the present position of surgery for benign prostatic obstruction (2 January, v. 31), but I do not think that his remarks about general surgeons in this field can pass without some comment. His sentence which ends "treating all kinds of surgical conditions as best they can" suggests that general surgeons are regarded as hack and do not have sufficient skill to be proper specialists. One could equally suggest that those who work only in small specialtie have not the skill to encombass the broad aspect of general surgery. Both suggestion are wrong. It is also inaccurate to imply that general surgeons are occasional prostatectomists. As a general surgeon, I personally perform over 50 prostatectomies a year, and I do not regard this as occasional I might add, in all modesty, that my mortality figures are lower than those quoted by Professor Blandy. Perhaps I do not do enough.
It is obvious that any surgical operation must be performed by a surgeon who has been properly trained and is fully experienced in the technique, but let us beware of over-specialization. There are more important factors in surgical results than the degree of specialization of the surgeon.-I am, etc.,

R. J. LUCK

Heatherwood Hospital,

Ascot, Berks

\section{Guthrie Test and Fungal Growth}

SIR,-Guthrie ${ }^{1}$ recommended that blood spots collected on paper for Guthrie testing should be at least $\frac{3}{8}$ in $(1 \mathrm{~cm})$ in diameter (but not more than $\frac{1}{2}$ in $-1.25 \mathrm{~cm}$ ) and should be air-dried. A sample was received for routine testing in this laboratory with a single large area of blood $45 \times 20 \mathrm{~mm}$ which appeared to have been inadequately dried before being put into the polyethylene envelope provided for protection. A Guthrie test showed a very high result and subsequent tests revealed widely differing phenylalanine levels (from over $40 \mathrm{mg} / 100$ $\mathrm{ml}$ to less than $4 \mathrm{mg} / 100 \mathrm{ml}$ ) in various parts of the blood spot. Repeat samples from the baby gave phenylalanine levels of less than $4 \mathrm{mg} / 100 \mathrm{ml}$ and an attempt was made to find the cause of the original elevated result.

Chromatography of a disc from the first sample showed abnormally high levels of all amino acids. Contamination of the card by an organic agent was discounted because no area outside the blood spot showed growth on inhibition assay and none of the likely liquid contaminants (for example, milk feeds) was found to give similar chromatographic results even when hydrolysed with hydrochloric acid.

It was recalled that a similar card had been rejected some time previously because of the visible presence of a fungus on the surface of the damp blood spot. The fungus was isolated and identified as Scopulariopsis brevicaulis, common airborne contaminant sometimes isolated from onychomycoses. The fungus was used in a number of experiments designed to produce false-positive results. (It was not possible to use mat arial from the elevated sample as the card had been autoclaved on receipt.) PKU Test Agar (Oxoid) supported the growth of the fungus, but no appreciable germination of the Bacillus subtilis spores occurred.

To reproduce conditions similar to those which could be encountered in practice blood was lightly inoculated with the fungus. This was added to Guthrie cards to give very large areas of blood. Samples which were immediately dried and samples of the fungal culture alone gave negative results when Guthrie-tested one week later. Fungal growth was visible on those blood samples on cards which were placed in polyethylene envelopes after incomplete drying and kert at room temperature for one week. High levels of phenylalanine were found in these samples, and chromatography showed raised levels of all amino acids.

To obtain an indication of the likelihood of fungal growth on Guthrie cards when conditions were suitable, cards were handled for a few minutes by volunteers not working in the laboratory and then partly flooded with blood from random fresh sequestrene samples. The cards were put wet into the envelopes and left for one week at room temperature. Guthrie tests showed appreciable increases in some samples. Preliminary results showed that fungal contamination is not uncommon.

It is, therefore, postulated that the original raised result was due to fungal activity on the blood which occurred after the card was placed wh:le wet into the polyethylene envelope and because the large volume of blood retarded the drying-out of the blood spots within the envelope. Levy et $a l^{2}$ have recently shown elevation of amino acids in sera in which marked bacterial contamination was intentionally introduced. They concluded that bacterial contamination was probably one factor in the generalized amino acid increases noted in an occasional random serum spesimen.

Fungal contamination of specimens may escape notice and was hitherto unsuspected by us. Adherence to the recommended size of blood spots should minimize this problem. In this particular case the high test result led to great parental anxiety. We should like to bring this possibility to the notice of those responsible for the quality of Guthrie specimens and to suggest the observance of rigid standards for acceptance and rejection of specimens for testing.-We are, etc.,

R. L. NEWMAN D. J. T. STARR

Queen Mary's Hospital for Children 1 Guthrie, R., and Susi, A., Pediatrics, 1963, 32,
338.
2 Levy, H. L., Karolkewicz, V., Houghton, S. A.,
and MacCready, R. A., New England fournal
of Medicine, 1970, 282, 1455.

\section{Mental Disturbance in Doctors}

SIR,-YYour leading article ${ }^{1}$ reasonably concludes that improved teaching of psychiatry in the medical curriculum and later might have a preventive value on the incidence of psychiatric illness and suicide occurring among doctors, but it makes no mention of the specific points put forward in my letter two months earlier. ${ }^{2}$ With the probable foundation of a royal college of psychiatrists in the offing, the time may now be ripe to emphasize that doctors do not differ basically from other members of the gregarious human race in requiring the right amount and quality of social contact for their well-being. As things are, however, they get far more than their share of intense exchange, mostly of an unhappy kind, at times overwhelming even of professionally enhanced resilience to emotional infection. ${ }^{3}$ Suicide in this context is probably only the tip of an iceberg of total affective overload supported.

The long-recognized, and by some deplored, tendency of many doctors to treat their patients as diseases rather than people may be a protective mechanism against morbidly excessive numbers of close social contacts, especially of the dispiriting kind. There must be many other factors, however, to azcount for the varying susceptibility to depression of the different specialties and sub-divisions within medicine." Anaesthetists, who approach the head of the suicide rate table with psychiatrists, mav even provide an exception which proves the general rule. Almost paradoxically they suffer from relative social deprivation, silently cooped up mainly with unconscious patients for company.-I am, etc.,

J. P. CRawford

Ide Hill, Kent

Brittsh Medical fournal, 1969. 4. 448.

Crawford, J. P., British Medical fournal, 1969, 3 , 779.
Crawford. J. P., British fournal of Psychiatry, 1965, 4 World Medicine, 1968, 3, No. 17, p. 39. 